\title{
ALUNOS COM AUTISMO: UM ESTUDO DOS TEMPOS E DOS ESPAÇOS DE ESCOLARIZAÇÃO
} STUDENTS WITH AUTISM: A STUDY OF TIMES AND PLACES OF SCHOOLING ESTUDIANTES COM AUTISMO: UM ESTUDIO DE LOS TIEMPOS Y ESPACIOS DE
LA ESCOLARIZACIÓN

Marcia Doralina Alves* marciapsico@terra.com.br

Taís Guareschi** tais.guareschi@gmail.com

Maria Inês Naujorks*** minau199o@gmail.com

REVISTA PEDAGÓGICA

Revista do Programa de Pós-graduação em Educação da Unochapecó | ISSN 1984-1566

Universidade Comunitária da Região de Chapecó | Chapecó-SC, Brasil Como referenciar este artigo: ALVES, M. D.; GUARESCHI, T.; NAUJORKS, M. I. Alunos com autismo: um estudo dos tempos e dos espaços de escolarização. Revista Pedagógica, Chapecó, v. 19, n. 40, p. 262-285, jan./abr. 2017. DOI: http://dx.doi.org/10.22196/rp.v19i40.3753

RESUMO: Este artigo tem como objetivo discutir, por meio de um estudo teórico, os tempos e os espaços de escolarização propostos aos alunos com autismo ao longo da história. Para tanto, desenharemos o caminho trilhado, no que se refere à criação de lugares escolares especializados, até a inclusão escolar desses alunos no sistema comum de ensino. A ênfase recairá sobre a análise do tempo e dos espaços escolares estabelecidos na contemporaneidade frente ao imperativo da inclusão. Diante do entrecruzamento de um discurso social que preconiza uma educação para todos, cabe perguntar se, na organização das tarefas educativas, há lugar para o tempo singular de cada sujeito, entendido aqui a partir da noção psicanalítica de singularidade.

Palavras-chave: Autismo. Escolarização. Inclusão escolar. Tempos de escola.

ABSTRACT: This paper aims to discuss, by means of a theoretical study, times and places of schooling proposed to students with autism throughout history. In order to do so, this study will be designed in relation to the creation of specialized schooling places until the school inclusion of these students in the regular school system. The emphasis will be on the analysis of school times and spaces contemporarily established towards inclusion. In the face of an intertwined social discourse that calls for education for all, it is possible to question whether in the organization of educational tasks, there is a place for the singular time of each subject, understood here under the notion of psychoanalytical singularity.

Keywords: Autism. Schooling. School Inclusion. Time of School.

RESUMEN: Este artículo tiene como objetivo discutir, a través de un estudio teórico, los tiempos y los espacios de escolarización ofrecido a los estudiantes con autismo a lo largo de la historia. Por lo tanto, vamos a dibujar el camino recorrido, por lo que respecta a la creación de plazas en las escuelas especiales para la inclusión escolar de los estudiantes en el sistema educativo común. Se hará hincapié en el análisis de los espacios de tiempoy escolares establecidos frente al imperativo contemporáneo de la inclusión. En la intersección de un discurso social que aboga por la educación para todos, la pregunta es, en la organización de las tareas educativas, hay espacio para el momento único de cada sujeto, entendido aquí desde la noción psicoanalítica de la singularidad.

Palabras clave: Autismo. La escolarización. La inclusión escolar. Días de escuela. 
* Professora Doutora do Departamento de Educação Especial da Universidade Federal de Santa Maria / UFSM.

\footnotetext{
** Professora de Educação Especial. Doutora em Educação pela Universidade Federal de Santa Maria/UFSM.

*** Professora Doutora do Departamento de Educação Especial da Universidade Federal de Santa Maria / UFSM.
}

\section{INTRODUÇÃO}

A constituição do tempo e do espaço escolar para crianças e adolescentes que apresentam problemas em seu desenvolvimento foi bastante diversa no decorrer da história. Observamos um longo trajeto percorrido, iniciando este na exclusão desses sujeitos do sistema educacional, passando pela criação de espaços escolares especializados e culminando, por fim, com a sua inserção no sistema comum de ensino. Nesse percurso, muitas postulações e determinações quanto à educação desses sujeitos foram construídas, denotando que, a partir do fortalecimento do movimento de inclusão, o tempo e o espaço de escolarização para esses alunos têm se configurado cada vez mais de forma universal.

Para fins deste estudo, entendemos o processo de escolarização como uma aposta no trabalho educacional e na oferta de instrumentos destinados à organização cognitiva de alunos com autismo. Dessa forma, a escola poderá ser um veículo para a reordenação do campo simbólico dessas crianças, instância tão precariamente constituída em função de um imaginário empobrecido, uma vez que a imaginação e a fantasia são praticamente ausentes. Acreditamos que, ao serem escolarizadas, as crianças com autismo possam se beneficiar do valor social da escola, reorganizando o laço com o outro e com a cultura na contemporaneidade.

Com base nesses pressupostos, este artigo tem como objetivo discutir, por meio de um estudo teórico, o tempo e os espaços de escolarização propostos aos alunos com autismo. Para tanto, desenharemos o caminho trilhado na história no que se refere à escolarização desses alunos, dando ênfase à análise do tempo e do espaço escolares estabelecidos atualmente diante do imperativo da inclusão. Desejamos também, perante um discurso social que preconiza uma educação para todos, questionar se, hoje, nas escolas, há lugar para o tempo singular de cada aluno, entendido aqui a partir da noção psicanalítica de singularidade.

As propostas de escolarização para os alunos com autismo são resultado de construções sociais. Observamos isso desde o isolamento dessas pessoas, no final do século XIX, a partir de aparatos como asilos e hospitais psiquiátricos, até a sua inclusão em escolas regulares no século XXI. Ao voltarmos nosso olhar para a história dessa escolarização, percebemos que ela se confunde com a dos sujeitos que apresentam deficiência intelectual. Isso porque o autismo, tal como o conhecemos hoje, tem uma história relativamente recente, uma vez que o primeiro recorte desse problema psíquico foi realizado na década de 1940 pelo psiquiatra Leo Kanner.

Kupfer $(1999,2001)$ afirma que o autismo é uma criação moderna e problematiza: será que o autismo sempre existiu? A autora ressalta que é preciso considerar a dimensão cultural e o valor de "[...] certa determinação discursiva em circulação no mundo contemporâneo incidindo sobre 
o autismo" (KUPFER, 1999, p. 99). Dessa forma, é preciso considerar o que se afirma sobre esse problema psíquico grave e o lugar que ele ocupa na contemporaneidade.

A fim de problematizar essa questão, Kupfer (1999, 2001) expõe três teses. A primeira delas é a de que os autistas sempre existiram, conforme atestam as lendas irlandesas das crianças-fadas, as quais tinham suas almas roubadas por duendes e passavam a apresentar manifestações semelhantes às do autismo. Além disso, a autora menciona que essas crianças também apareceram na literatura. Kupfer $(1999,2001)$ postula que essas crianças possivelmente foram confundidas, até o século XX, com crianças com deficiência intelectual. A segunda tese, oposta à primeira, de que os autistas sempre existiram, é defendida por Volnovich; para esse autor, o autismo seria uma criação moderna, uma vez que a loucura é produzida histórica e politicamente (KUPFER, 1999, 2001). Por fim, Kupfer (1999) afirma que a terceira tese poderia solucionar essa oposição. De acordo com a autora:

Para essa última, o autismo será um significante moderno que dá nome a um fenômeno estrutural na constituição do sujeito, nome esse que o representa, porém dentro de uma particular inflexão do discurso social contemporâneo, e que, ao representá-lo, o recria. Esse nome moderno, criado por Kanner, recorta e cria um novo discurso que o situa e lhe dá um lugar no mundo contemporâneo. Cria, com o poder de criação de um significante, um novo autista. Que prolifera, vai à mídia, aos filmes, que enternece. Significa algo para a sociedade hoje, e é por ela significado a partir das modelizações sociais a sua disposição (KUPFER, 1999, p. 100).

Logo, o autista de hoje não é o mesmo do mundo antigo, uma vez que o discurso social e o lugar moderno em que esse indivíduo é colocado produzem efeitos subjetivos na sua constituição. Além de haver uma estrutura autista, “[...] há também o significante 'autismo', cunhado pelo social, que recria essa estrutura, tendo efeitos sobre o modo como essa criança é apresentada por seus pais, e sobre o modo como é tratada" (KUPFER, 1999, p. 10). Sendo assim, apresentar os sentidos dos discursos sobre o autismo é pensar em descrever uma história de forma a apontar continuidades e rupturas, mostrando com detalhes como a dimensão da cultura dá ao autismo a sua condição moderna.

\section{DA EXCLUSÃO À ESCOLARIZAÇÃO: O NASCIMENTO DAS PROPOSTAS PEDAGÓGICAS}

Entre as civilizações antigas, a Grécia ocupa um lugar de destaque, podendo ser considerada o berço da Pedagogia. Nela, o conhecimento passou a ter outro significado, 
a ser criticado e comprovado, e a mística e a religião deixaram de ter um status exclusivo. Em Atenas, a educação espartana, cujo objetivo era enaltecer a força e a disciplina, ainda se fazia presente, inspirando-se na poesia homérica, que apresenta modelos de virtude, coragem e força. Considera-se, de certa forma, os poetas (principalmente Homero e Heródoto) como os primeiros educadores da humanidade, homens cuja função era perpetuar a cultura em sociedades que ainda não conheciam os recursos da escrita (GAUTHIER; TARDIF, 2010). Esse cenário começou a mudar quando os poetas educadores passaram a ser alvo de críticas pelos filósofos em função das suas concepções de homem e de mundo.

O conflito de ideias entre poetas e filósofos levou os gregos a se perguntarem sobre novas formas de educação. Vale lembrar que essa preocupação se deu em relação aos adolescentes, não atingindo a infância. Nesse contexto,

[...] os gregos nunca conheceram essa instituição que se chama escola, instituição concebida como um lugar permanente e coletivo ao qual vão todas as crianças para se submeterem à ação comum de professores que aplicam um mesmo programa. (GAUTHIER; TARDIF, 2010, p. 47).

Sendo assim, os gregos não desenvolveram uma pedagogia da infância. Segundo eles, a ideia de educação apenas começava quando as pessoas se tornavam capazes de pensar autonomamente. Nesse cenário, as pessoas deficientes/desviantes/diferentes eram mortas ou abandonadas à sua sorte. Para Amaral (1995), essa era uma prática chamada de "exposição".

Despontou, no século V a.C., um exemplo de educação grega, com o objetivo de educar o indivíduo como homem e cidadão: a Paideia. Segundo Aranha (2006), ao discutir os objetivos da Paideia, os gregos esboçaram as primeiras linhas sobre a ação pedagógica, influenciando enormemente a cultura ocidental. Os expoentes desse novo ideal de formação foram os sofistas, os professores da sabedoria, sábios que, naquela época, já se perguntavam sobre o que, como e para que ensinar; dentre esses, Sócrates, Platão e Aristóteles lutaram pela educação integral do homem, que consistia na formação da mente pela filosofia e pelas ciências; do corpo pela ginástica; da moral e dos sentimentos pela música e pelas artes (GADOTTI, 2002). Consideram-se os sofistas como os primeiros professores, sendo seus alunos chamados de clientes, pois os cursos oferecidos pelos sábios eram pagos e o aluno deveria deixar sua família para realizá-los. A noção de Paideia como ideal de formação humana, assim, ganhou força e consolidou-se como um meio pelo qual o homem torna-se cidadão.

Conforme Gauthier e Tardif (2010), a educação dos sofistas não foi centrada em educar crianças em uma classe; ademais, eles ignoravam o que fosse um sistema escolar 
ou a pedagogia infantil. A sua orientação se dirigia a homens que deveriam ser transformados graças à palavra e à persuasão. Sendo assim, os pensadores gregos criaram os questionamentos sobre os fundamentos da educação, enquanto os problemas concernentes à escola e à pedagogia viriam posteriormente, na Idade Média, com o surgimento do Cristianismo.

Com a educação jesuítica (chamada de "escolástica”), na Idade Média, a Igreja passou a ter um lugar de destaque e se tornou responsável por ensinar os textos sagrados, com o objetivo de moralizar a sociedade e convertê-la ao Cristianismo. Assim, a escola nasceu frente a um projeto moral comum ao determinar que, para ser cristão, é preciso ser civilizado e educado. Para tal, escola e Cristianismo operaram conjuntamente, e a pedagogia passou a ser fortemente influenciada pela Igreja, resultando em mudanças na educação (CAMBI; TREBISACCE, 1999).

Apoiada na ideia de uma educação cristã, a religião tornou-se hegemônica e invadiu a pedagogia e as escolas. Para Dussel e Caruso (2003), a escolarização foi uma das tarefas favoritas dos jesuítas, cujo método de ensino se dava a partir de um texto básico, criado em 1599: a Ratio Studiorum. Os autores apontam que a sala de aula era um espaço recortado da vida diária e o curriculum constituía-se basicamente de latim, grego e ensinamentos religiosos. As práticas pedagógicas dos jesuítas se incumbiam, portanto, da formação e da conversão do cristão.

É importante notar que, na Idade Média, a infância era tida como uma fase negativa da vida, que necessitava de confinamento e de correção. Para esse fim, mantidas longe das famílias, as crianças eram submetidas a uma educação rígida nas escolas. Segundo Hillesheim e Guareschi (2006), ocorreu, nesse período, uma produção discursiva sobre a infância que a entende como um momento a ser superado, seja pela criança estar imersa no pecado, seja por ser desprovida da razão, devido ao fato de não possuir linguagem (infante significa "o que não fala"). Conforme Ghiraldelli Júnior (2000), desprovida de razão, a criança não possuiria o reflexo da condição divina que haveria em nós. Em se tratando de pessoas com deficiência, de acordo com Amaral (1995), a Idade Média reconhecia a existência da alma do deficiente e recomendava que este fosse açoitado, uma vez que era considerado possuído pelo demônio, porque lhe faltavam a razão e a perfeição.

Com o fim da Idade Média, as questões abstratas e ligadas a Deus deixaram de ser o foco e passou-se a se concentrar nas discussões em torno do homem, com ênfase na razão. Anunciava-se, então, um movimento que lançaria as bases da educação moderna: o Renascimento. Durante esse período, surgiu a ideia de um programa pedagógico para "ensinar tudo a todos" (COMENIUS, 2011), bem como a emergência do termo "classe". Sob a ótica da escolarização das massas, situamos o ideal de uma figura importante da Modernidade: Jan Amos Comenius, que defende que "todos 
têm desaber tudo" e que os educadores devem "ensinar tudo a todos", ideias que compõem o chamado ideal pansófico de Comenius (NARODOWSKI, 2006, p. 26).

Comenius acreditava na natureza educável do homem e na capacidade de entendimento de todos os indivíduos. Nos pressupostos da sua pansofia, está que todos que nasceram homens são educáveis. Com o advento da Modernidade, surgiu a Pedagogia como ciência, buscando controlar todas as variáveis do processo de aprendizagem, articulando-se em torno da didática, da disciplina e das práticas repressivas. Foi também nesse período que se viu a transição do controle da educação da Igreja para o Estado, inaugurando uma nova racionalidade educativa, pautada nos conceitos de educação, natureza e liberdade, e um novo sentido para "educação", que era embasada, então, no pensamento de Rousseau, os processos de ensinar e aprender.

De acordo com Cambi e Trebisacce (1999, p. 215), frente ao cenário da Idade Moderna, "[...] a cientificidade da educação ganha mais espaço com todo um arsenal lógico-experimental, típico das ciências modernas". Com o discurso das ciências, assistiu-se, então, a uma vida social que preparava os homens para serem cidadãos; com isso, a educação sofreu renovações a partir de uma escola estatal, nacional e laica - herança que, mais tarde, chegou à contemporaneidade por meio de uma pedagogia marcada com o selo das escalas e das medições. Como expoentes dessa época, surgiramos pedagogos da infância anormal, dentre os quais estão Maria Montessori e Jean-Ovide Decroly, que observaram as crianças recolhidas nas instituições especiais e que, através de experimentos, procuraram descobrir as causas que determinavam seu desenvolvimento. Esses novos pedagogos, em sua maior parte, eram advindos da Medicina e da Psicologia.

Conforme Hamilton (1996), o nascimento do curriculum trouxe um direcionamento maior de controle tanto ao ensino quanto à aprendizagem. A distribuição dos alunos em classes foi acompanhada de uma formalização de conteúdos e de métodos, resultando em um processo educacional. Com a instrumentalização da escola, os processos de socialização dos sujeitos nas instituições escolares passaram a se articular em função de espaços e tempos definidos. Com tal regulação do espaço e do tempo, a escola passou a controlar minuciosamente as atividades e os deslocamentos dos alunos. Nesse cenário, o exame surgiu como um dispositivo fundamental para classificar, corrigir, medir e enquadrar aqueles considerados fora da norma.

Essa nova forma de perceber e organizar o espaço e o tempo permite um controle detalhado do processo de aprendizagem, permite o controle de todos e de cada um dos alunos, faz com que o espaço escolar funcione como uma máquina de aprender e ao mesmo tempo possibilita a intervenção do mestre em qualquer momento para premiar ou castigar 
e, sobretudo, para corrigir e normalizar. (VARELA, 1996, p. 84).

Diante desse novo sentido dado à infância, a escola manipularia os alunos e não duvidaria em lembrá-los de que, no caso de uma possível inadaptação escolar, a culpa seria somente deles. Nesse caso, conforme cita Varela (1996), o professor não hesitaria em enviar o aluno para uma escola especial para deficientes.

Nesse período da história, o Estado assumiu a educação pública e passou a controlar a sua dinâmica. Aliado a isso, está o fato de que, com a Revolução Industrial, os pais encontravam-se trabalhando nas fábricas. Nesse ínterim, onde ficavam as crianças? Vemos aí o problema da delinquência como fator a ser controlado, pois um enorme contingente de crianças não tinha para onde ir. A infância requeria cuidados e, para isso, a escola pública e gratuita era a solução.

A escola obrigatória e pública, em meados do século $\mathrm{XX}$, destinava-se a crianças de classes populares, que, nas palavras de Varela (1996), se encontravam em um estágio de selvageria. Para estas crianças, a escola pública representava uma forma de domesticação, pois lhes ensinava noções de civilidade. Para aqueles que resistiam à escola disciplinar, surgiram diferentes instituições destinadas aos "[...] cretinos, sem sentimentos, desconfiados, frios, desmemoriados, memoriosos, visionários, terroristas, surdos-mudos, cegos, de gostos grosseiros, inexpressivos, imbecis, histéricos, hiperestésicos, passionais e masturbadores" (VARELA, 1996, p. 89). Tendo em vista indivíduos tão singulares, pode-se pensar que sujeitos com autismo poderiam figurar nessa lista de "selvagens", inaugurando um novo espaço para a infância anormal.

Para Narodowski e Hors (1999), esse olhar minucioso e controlador diante da vida ocorreu paralelamente a uma construção histórico-social importante: a infância. Esta, como anteriormente destacamos, influenciou o nascimento da Pedagogia e das escolas e se tornou, a partir do século XVII, uma preocupação moral:

A criança deixou de ser misturada aos adultos e de aprender a vida diretamente, através do contato com eles. A despeito das muitas reticências e retardamentos, a criança foi separada dos adultos e mantida à distância numa espécie de quarentena, antes de ser solta no mundo. Essa quarentena foi a escola, o colégio. Começou então um longo processo de enclausuramento das crianças (como dos loucos, dos pobres e das prostitutas) que se estenderia até nossos dias, e ao qual se dá o nome de escolarização. (ARIÈS, 1978, p. 11).

Como já dissemos anteriormente, na sociedade medieval, o sentimento de infância não existia, pois a criança estava misturada aos adultos, constituindo-se como mão 
1 Nesse sentido, vale lembrar que a debilidade mental somentetomouforça de categoria clínica autônoma no século XX, através da classificação da Psiquiatria Infantil (SANTIAGO, 2005). de obra, nas fazendas, juntamente com seus pais. Como braços aliados para o trabalho, elas se configuravam como uma possibilidade de futuro melhor para suas famílias. Outra ideia que se tinha das crianças era a de que elas deveriam ser curadas de suas leviandades e vícios, pressuposto instaurado pela doutrina cristã, que criou as escolas para civilizar seus pequenos fiéis. Esse princípio de educação compreendia também o grupo dos deficientes mentais. A socialização surgiu no final da Idade Média/início da Modernidade (VARELA, 1996) como forma de distanciar o homem da animalidade, convertendo-o em um ser civilizado.

Durante a Renascença, surgiram as classificações das doenças e das anomalias a partir da teoria da degeneração de Morel. A nosografia dos estados mentais de Morel permitiu a proliferação da categorização das doenças relacionadas ao comportamento, bem como a sua medicalização, além de possibilitar o nascimento da Psiquiatria. Nessa época, as "anomalias" faziam parte de um grande grupo que compreendia os idiotas, os instáveis (desequilibrados e impulsivos) e os imbecis ${ }^{1}$. Conforme Kupfer (1997), os autistas dessa época estavam misturados a esse contingente, uma vez que o olhar médico ainda não os havia subtraído desse grande grupo. Esse fato explica porque reina certa dúvida quando nos referimos a esses sujeitos na contemporaneidade. Muitas crianças com autismo, ainda hoje, são confundidas com deficientes mentais, independentemente de terem associada ou não à sua condição um déficit cognitivo.

Seguindo a esteira apresentada por Kupfer (1997), é possível refletir, a partir das colocações de Lobo (2008), que as classificações médico-pedagógicas do final da Idade Média e do início do Período Moderno ainda são fortemente empregadas, principalmente quando se trata de distinguir as crianças educáveis das ineducáveis. Nas observações desta autora, é ilustrativo um estudo feito no Brasil sobre a denominação das crianças educáveis e ineducáveis. Tal estudo diz respeito à primeira amostra estatística realizada pelo professor Clemente Quaglio, da Escola Normal de São Paulo, que, em 1913, realizou um teste de inteligência para identificar os deficientes mentais. A partir dele, podemos inferir que os sujeitos com autismo poderiam se encontrar entre aqueles que espalhavam a desordem e a indisciplina:

Na instância extrema da maldade, em que reinavam o idiota masturbador e colérico e o imbecil pervertido, instalam-se novos ocupantes - os anormais psíquicos verdadeiros que, segundo Quaglio, são impacientes, irritáveis, coléricos, essas crianças causam desespero aos pais [...] postas na escola são a causa permanente de distúrbios [...]. De modo que o único desejo do mestre é de se ver livre delas. (LOBO, 2008, p. 382).

Outro aspecto a ser destacado no estudo de Kupfer (1997)refere-se às pesquisas de Kanner sobre o autismo 
2 Desiré Magloire Bourneville foi um médico francês, pesquisador de doenças nervosas e infantis. Ele lutou para a criação, regulamentação e implantação de classes especiais para crianças anormais nas escolas de $\mathrm{Pa}$ ris. Seu trabalho teve ampla repercussão no Brasil, o que resultou na criação do Pavilhão Bourneville no Rio de Janeiro. infantil. Conforme o autor, foi do grupo dos deficientes mentais que Kanner, em 1943, isolou essa categoria nosológica (KUPFER, 1997). Para a sociedade da época, todas as crianças do grupo dos deficientes mentais estavam fadadas ao destino cruel do asilamento e, juntamente com elas, como constatamos, os sujeitos com autismo.

As perspectivas dos pedagogos da infância anormal se estenderam ao século XX e a área da Educação Especial ganhou força. O médico Jean-Marc Gaspar Itard inaugurou a prática de reeducação ao tratar de Vitor, um menino considerado por ele idiota, que, após uma tentativa de assassinato, fora deixado nos bosques de Aveyron, na França, para morrer (O GAROTO..., 1970). O tratamento de Vitor marcou, no início do século XIX, o nascimento da Psiquiatria Infantil. Banks-Leite e Souza (2000) apontam que a forma como Itard procedeu em suas intervenções fez dele um verdadeiro precursor da Psicologia e da Pedagogia Experimental. As autoras afirmam também que Kanner, ao descrever os casos de autismo, em 1943, faz referência a Itard como o precursor das pesquisas sobre esse domínio de investigação.

Vimos que, até o final do século XIX, os sujeitos com autismo fizeram parte do grupo das crianças com deficiência mental, restando-lhes o título de incuráveis e a reclusão nos asilos. Conforme Lobo (2008, p. 393),

O território das separações dos indivíduos considerados defeituosos em espaços físicos diferentes começou a delinear-se em meados do século XIX com a criação (cronológica) do Hospício de Pedro II, do Imperial Instituto dos Meninos Cegos, do Instituto dos Surdos-Mudos e, já no início do século XX, do Pavilhão-Escola Bourneville para Crianças Anormais, no interior do então Hospício Nacional dos Alienados.

A autora afirma que a superlotação e a mistura entre os curáveis e incuráveis e, principalmente, entre adultos e crianças no interior do Hospício Nacional dos Alienados foi o estopim para a criação, em 1904, do Pavilhão Bourneville $^{2}$, o primeiro estabelecimento fundado, no Brasil, para crianças anormais, que comportava duas salas, uma para meninas e outra para meninos (chamados de retardados ou degenerados). Januzzi (2006) as descreve como locais que dispunham de material didático, como objetos de formas geométricas, tecidos e outros materiais de várias texturas e cores, além de instrumentos de percussão. Mendes (2010) aponta que outro marco na história da Educação Especial no Brasil foi a criação do Instituto dos Meninos Cegos, em 1854, e do Instituto dos Surdos-Mudos, em 1857. Ambos inauguraram, na prática, as instituições especializadas das chamadas "deficiências”. Segundo Lobo (2008, p. 380): 
Critérios médicos mesclam-se aos pedagógicos, e a anormalidade infantil passa gradativamente a referir-se às possibilidades de escolarização. Ou seja: os sintomas que começam a aparecer com o ingresso da criança na escola transformam-se em critérios de separação classificatória e demarcam a inclusão em espaços institucionais diferentes: as crianças das escolas regulares, as das escolas especiais e as de asilo por serem educáveis.

Para Cirino (2001), os asilos se encarregaram de dar abrigo aos "idiotas" ou retardados que não necessitavam de um tratamento, mas sim de um saber que vislumbrasse a sua aprendizagem. Para tanto, tiveram de produzir um conhecimento que fosse além das noções que possuíam sobre a doença mental. Foi Séguin, renomado médico da época e aluno de Jean Itard, que fundou, no Hospital Bicêtre de Paris, uma "escola especial" para crianças deficitárias, inaugurando as primeiras noções de Psicopedagogia, uma vez que o tratamento da infância implicaria o surgimento de instituições voltadas para as questões pedagógicas e menos para o atendimento médico.

Os critérios médicos passaram, então, a ser amplamente utilizados para distinguir os anormais completos (ou ineducáveis) e os incompletos (educáveis) das demais crianças escolares. No final do século XIX/início do século XX, presenciamos o advento dos estudos sobre a infância, mais especificamente no que se refere ao nascimento da Psiquiatria da Criança. Foi nesse cenário que se inaugurou a preocupação com o mundo infantil. A racionalidade científica tomou corpo, e a Medicina e a Psicologia passaram a mensurar e classificar as crianças, realizando divisões entre aqueles que poderiam se beneficiar com a escola e aqueles alunos ineducáveis. Nessa época, a Psicometria teve também sua ascensão ao localizar os indivíduos que se enquadravam dentro de padrões de normalidade ou que permaneciam fora deles. Segundo Cirino (2001), foi em 1905 que surgiu a primeira escala de desenvolvimento da inteligência que serviu de critério para selecionar e triar os indivíduos para as "classes especiais".

Nesse período, assistiu-se ao movimento da Escola Nova, que perdurou até a Segunda Guerra Mundial. Esse movimento internacional preconizava a reforma educacional diante de um mundo que crescia velozmente. Conforme Dussel e Caruso (2003), os "escolanovistas" queriam que o ensino se adaptasse à criança, considerada boa e flexível, de forma que ela servisse de base para a preparação da sala de aula. Dentre as figuras importantes desse movimento para a renovação do ensino, destacam-se John Dewey, Maria Montessori, Jean-OvideDecroly e Jean Piaget. No contexto brasileiro, temos a psicóloga russa Helena Antipoff, que, em 1929, radicou-se no Brasil e que criou serviços de diagnóstico e classes e escolas especiais para os excepcionais - designação, aliás, por ela criada. A psicóloga foi 
responsável também pela criação da Sociedade Pestalozzi de Minas Gerais que, em 1945, passou a se expandir pelo Brasil (JANUZZI, 2006). Além disso, Mendes (2010) reitera que Helena Antipoff participou ativamente do movimento que culminou na implantação da APAE, em 11 de dezembro de 1954, no Rio de Janeiro. A psicóloga influenciou um grande contingente de profissionais que passaram a se dedicar à área da Educação Especial nos anos seguintes.

Em meados dos anos de 1960, vimos nascer o Princípio de Integração Social e Escolar, que se centra na participação igualitária de todas as pessoas nas instituições sociais, sendo a escola uma das representantes desse movimento. Carvalho (2005, p. 25) refere-se à integração como "[...] um processo de educar-ensinar, juntas, crianças ditas normais com crianças portadoras de deficiência, durante uma parte ou em período integral na escola”. Para a eficácia desse processo, os alunos deveriam se adaptar à dinâmica da escola.

No que diz respeito ao tempo e ao espaço escolar dos alunos com autismo, destacamos a importância da criação, em setembro de 1969, da ÉcoleExpérimentale de Bonneuil-sur-Marne na França. A escola experimental de Bonneuil foi fundada pela psicanalista Maud Mannoni, pautada em uma perspectiva de não segregação, para acolher crianças e adolescentes excluídos do sistema escolar, familiar ou social, como os alunos com autismo. A criação dessa escola ocorreu em meio ao movimento antipsiquiátrico, na Europa, que questionava a compreensão da doença mental e os modelos de tratamento das instituições psiquiátricas clássicas e propunha novas formas de atenção em saúde mental.

Na Escola Experimental de Bonneuil, foi oferecido a essas pessoas um lugar para viver bastante diferente dos hospitais psiquiátricos. Nessa proposta, os sujeitos não permaneciam "mergulhados em banhos de tratamento", pois se buscava "acolher o sintoma mais do que analisá-lo”, como refere Mannoni (1992, p. 59) em uma entrevista sobre a instituição; sendo assim, o tratamento analítico não era realizado no interior de Bonneuil. As crianças e os adolescentes recebidos na instituição deixavam "seus rótulos de loucura do lado de fora", de forma que sua trajetória ou as atividades realizadas não eram predeterminadas com base em seus diagnósticos médicos: "Lá dentro, o importante é atravessar, ainda que de forma precária, um processo de escolarização, ferramenta fundamental para uma futura reinserção no circuito social produtivo" (MANNONI, 1992, p. 58). Para seu funcionamento, a escola era registrada oficialmente como um hospital durante o dia e como um lar terapêutico à noite. Porém, Lajonquière e Scagiola (1998) ressaltam que o significante para crianças e adolescentes era o de "escola" (por vezes, "escola de loucos";mas, ainda assim, uma escola) e não o de "um lugar de doentes"; na porta de entrada, aliás, estava escrito somente $E s$ cola Experimental (LAJONQUIÈRE; SCAGIOLA, 1998). 
Evidentemente, o significante "escola", ao invés de "hospital" ou "manicômio", produz efeitos nos sujeitos que frequentam a instituição. Conforme salienta Jerusalinsky (2004, p. 150), "[...] a escola não é socialmente um depósito como o hospital psiquiátrico, a escola é um lugar para entrar e sair, [...] alguém que frequenta a escola se sente mais reconhecido socialmente do que aquele que não frequenta”.

O conceito de instituição estourada baliza a montagem institucional da escola. Nesse sentido, observamos uma abertura da instituição para o mundo exterior, uma vez que Bonneuil é um lugar de passagem, do qual sempre se parte por determinado tempo ou definitivamente. Esse conceito visa a proteger o sujeito do "perigo da institucionalização da sua 'doença”" (MANNONI, 1977, p. 141).

Considerando a noção de instituição estourada, são oferecidas às crianças e aos adolescentes atividades dentro e fora da escola. Essas atividades contemplam os planos da imaginação e da realidade (MANNONI, 1992). O plano da imaginação está vinculado aos ateliês, em que a criação tem papel de destaque, dos quais os alunos poderão escolher ou não participar; são oferecidos ateliês de música, de teatro, de pintura, de dança, de escultura etc., e outros podem ser criados mediante o interesse das crianças e dos adolescentes. Esses ateliês são organizados com rituais de início e de fim. O plano da realidade é contemplado pelas atividades escolares propriamente ditas, por trabalhos realizados com artesãos da região e por trabalhos efetivos no exterior da instituição, como em construções, por exemplo. Assim, esse plano oferece às crianças e aos adolescentes atividades de escolarização no interior da instituição e trabalhos no exterior, visando à inserção social e à aprendizagem de um ofício. Em relação ao exterior, esses sujeitos circulam, sempre acompanhados por profissionais ou estagiários da escola, também por outros espaços, como o consultório de análise, lieux d'accueiul (lugares de acolhida) e acampamentos de verão.

As atividades de escolarização propriamente ditas são desenvolvidas em aulas, no período da manhã, em pequenos grupos, de acordo com os interesses das crianças e dos adolescentes. Essas atividades contemplam, por exemplo, a escrita, a leitura e o cálculo. Em Bonneuil, é possibilitado ao aluno participar dos programas de ensino oficiais por meio da educação a distância ou através de aulas com professoras do sistema de ensino público, a fim de que possam ingressar ou retornar à escola comum. Para as crianças com dificuldades mais significativas, são criadas formas alternativas de aprendizagem (GEOFFROY, 2004).

Ainda em relação às atividades realizadas na escola, há as tarefas na cozinha. Nesse espaço, adultos e crianças designados para essa atividade preparam a refeição durante um período da manhã. Nesse lugar, estão aquelas crianças, adolescentes e adultos responsáveis pelo almoço, mas também aqueles que não suportam a permanência nas demais atividades. Na cozinha, há a circulação da palavra, 
por meio de conversas durante o preparo dos alimentos, e a presença da refeição, assim como em todos os lares. Para Petri (1998), o discurso que perpassa o trabalho é o de que a escola não serve como um lugar de tratamento, mas como um ambiente onde as crianças vivam e façam seus caminhos particulares, o que não tem espaço nas escolas regulares, onde o universal apaga a singularidade do sujeito.

Dando prosseguimento à nossa temática de estudo, nos anos 1990, assistimos ao surgimento de um novo paradigma: a Educação Inclusiva. No bojo da discussão desse movimento está o acesso de todos à educação escolar, fruto de um processo de democratização vivido pela população brasileira. Diante desse cenário, vimos ser proclamada a Declaração de Salamanca, aprovada pela Organização das Nações Unidas para a Educação, a Ciência e a Cultura (UNESCO), em 1994, que se tornou o vetor de toda a discussão que traga em pauta a educação para todos. Nela, os alunos da Educação Especial são designados como alunos com Necessidades Educativas Especiais, tratando-se de um marco na história da Educação Especial, pois o documento é categórico ao esclarecer que a escola deverá encontrar meios para que todas as crianças frequentem a escola, inclusive aquelas com deficiências graves (BRASIL, 1994).

\section{OTEMPO ESCOLARDIANTE DA PROPOSTA DE INCLUSÃO EDUCACIONAL: HÁ LUGAR PARA A SINGULARIDADE?}

Na contemporaneidade, o ideário da Educação Inclusiva se intensificou, especialmente a partir da década de 1990, com as publicações da Declaração Mundial de Educação para Todos (BRASIL, 1990) e da Declaração de Salamanca (BRASIL, 1994). No Brasil, o movimento da inclusão foi especialmente fortalecido com a publicação da Política Nacional de Educação Especial na perspectiva da Educação Inclusiva (BRASIL, 2008), documento que assegura o direito de todos os alunos a frequentar o ensino regular. Vale lembrar que os estudantes têm o seu direito à inclusão reservado desde a Constituição de 1988, ou seja, a Política Nacional apenas vem corroborar um direito à escolarização previsto anteriormente.

A Política Nacional de Educação Especial na perspectiva da Educação Inclusiva (BRASIL, 2008) e os documentos normativos que se seguiram, como a Resolução $n^{0}$ 4/2009 (BRASIL, 2009) e o Decreto $n^{0}$ 7.611/2011 (BRASIL, 2011), demarcam que todos os alunos devem frequentar o ensino regular, independentemente de suas necessidades educacionais específicas. Os alunos considerados público-alvo da Educação Especial (estudantes com deficiência, transtornos globais do desenvolvimento e altas habilidades/superdotação) deverão ser matriculados no Atendimento Educacional Especializado no contraturno, uma vez que os documentos sinalizam que a frequência a esse atendimento não deve prejudicar a presença do 
aluno nas aulas do ensino regular. Ademais, como lócus preferencial para a realização do Atendimento Educacional Especializado, os documentos indicam a sala de recursos multifuncionais da própria escola. Os alunos com autismo figuram entre os estudantes com transtornos globais do desenvolvimento, considerados público-alvo da Educação Especial.

Por meio da apreciação desses documentos, constatamos a universalização do tempo e do espaço escolar em uma educação que se pretende para todos - espécie de imperativo contemporâneo que torna os alunos reféns de um ideal educativo. Dessa forma, a orientação é de que todos os alunos considerados público-alvo da Educação Especial frequentem as quatro horas do ensino regular, garantindo as 800 horas distribuídas em 200 dias letivos, conforme determina a Lei de Diretrizes e Bases da Educação Nacional, Lei no 9.394/96 (BRASIL, 1996). Os espaços para a educação desses alunos são prioritariamente a escola de ensino regular e a sala de recursos multifuncionais, que oferece o Atendimento Educacional Especializado no contraturno.

No discurso da Educação Inclusiva, enunciados universalizantes, como educação para todos ou todos os alunos, são expressões que perpassam incisivamente o texto da lei. Esses enunciados podem ser constatados no excerto da Política Nacional de Educação Especial na perspectiva da Educação Inclusiva que segue:

Os sistemas de ensino devem organizar as condições de acesso aos espaços, aos recursos pedagógicos e à comunicação que favoreçam a promoção da aprendizagem e a valorização das diferenças, de forma a atender as necessidades educacionais de todos os alunos. (BRASIL, 2008, p. 12, grifos nossos).

Por mais sedutor que possa parecer, à primeira vista, um discurso que pretende incluir todos, sem distinção, ele também nos faz pensar se, diante de tanto furor inclusivo, há espaço para a singularidade, no sentido psicanalítico do termo. Garantir o mesmo espaço e o mesmo tempo de escolarização a todos poderá beneficiar sempre todos os alunos? Quais possibilidades poderiam ser criadas no encontro singular do aluno com a escola e com seu professor?

A obra freudiana evidencia algo que pretendemos tencionar nesta escrita: "[...] é quase impossível que o mesmo método educativo possa ser uniformemente bom para todas as crianças" (FREUD, 1988, p. 147), afirma o pai da Psicanálise nas primeiras décadas do século passado. Seria possível pensarmos que, se o mesmo método não beneficia a todos, como afirma Freud, talvez a mesma dinâmica escolar também não favoreça a aprendizagem de alguns alunos, pelo menos não em um primeiro momento. Nesse sentido, as postulações de Lajonquière (2003) sobre o discurso pedagógico hegemônico podem servir a esse tensionamento. 
No discurso pedagógico hegemônico, está implícita, não poucas vezes, a crença de que o professor detém o domínio do processo de aprendizagem. Então, partindo de certas etapas evolutivas, aplicam-se "métodos" e esperam-se resultados adequados dos alunos. Lajonquière (2003) afirma que, no discurso pedagógico hegemônico, há espaço garantido para afirmações behavioristas (oriundas da tradição behaviorista-reflexológica). A partir dessas afirmações, acredita-se que o aluno aprendeu quando há a consolidação de respostas corretas frente a estímulos. Dessa forma, o autor acredita que esse discurso "[...] repousa na ilusão (Freud: 'crença animada por um desejo') de que 'saber é poder', ou seja, que, conhecendo as leis da aprendizagem, o pedagogo detém o poder de calcular os efeitos dos métodos que coloca em ação [...]" (LAJONQUIÈRE, 2003, p. 15). Assim, o professor teria a pretensão de controlar o processo de aprendizagem, delimitando o que o aluno deve aprender e a melhor maneira de ensiná-lo, uma vez que "conhece as leis da aprendizagem", como refere o autor. Lajonquière (2003) afirma, ainda, que as crenças behavioristas não são as únicas que alimentam essa ilusão, citando também determinadas interpretações dos textos freudianos (que apostam na capacidade adaptativa do $\mathrm{Eu}$ ) e piagetianos e a psicologia das "faculdades mentais" ou cognitivismo.

Lajonquière discorre acerca do que denomina de discurso (psico)pedagógico hegemônico. Nesse discurso, quem fala (e sabe) acerca da Educação é o (psico)pedagogo, profissional que é "[...] detentor de uma série de saberes 'psi' aplicados que possibilitariam calcular os efeitos psicodesenvolvimentistas das metódicas intervenções 'educativas’ colocadas em ação” (LAJONQUIÈRE, 2002, p. 29). Mais uma vez, o autor põe em evidência a ilusão que permeia o discurso e o fazer pedagógico: conhecer as leis da aprendizagem para calcular o efeito dos métodos aplicados.

A ilusão de um saber completo e de domínio dos métodos educativos, além de colocar o professor na posição de "detentor do saber", alimenta um discurso pedagógico de pretensas certezas que busca o controle do processo de aprendizagem do aluno a partir do suposto conhecimento de suas leis.

Há que se problematizar o discurso sobre a inclusão de alunos com autismo expresso nos documentos legais e publicados pelo Ministério da Educação (MEC) e que propaga o direito de todos à educação. Evidentemente, não se está questionando o direito à educação dos estudantes com autismo;mas, diante desse imperativo, poderíamos perguntar sobre as possibilidades da sua escolarização, uma vez que cada sujeito se apresenta de forma única na escola. A relativa simplificação das orientações para o trabalho com esses alunos, encontrada em alguns documentos que chegam às escolas, gera impotência nos profissionais, que se veem confrontados, em sua prática, com estudantes que há pouco tempo não ocupavam o espaço escolar regular. 
Pereira (2013, p. 491) problematiza essa questão ao afirmar que:

[...] quanto mais professores encontram recursos, saberes, modos de atuar, experimentalismos e fórmulas bem-sucedidas creditadas em manuais, teses e livros, ao confrontá-los com sua própria atuação cotidiana, por vezes precária, menos eles se acham com potestade suficiente para exercer a sua arte. Em outros termos: quanto mais aparentemente hábil demonstra ser a prática do outro, menos apto o professor julga a sua própria; quanto mais mágica e ideal parecem ser as soluções dos manuais, menos bem-estar o professor tem ao se deparar com o que faz.

É possível perceber que essas soluções apresentadas em alguns textos, destinados a orientar os sistemas de ensino, mais parecem configurar-se como manuais prescritivos e causam certo mal-estar no professor, que poderá se sentir impotente diante do desafio de ensinar o aluno real. As experiências inclusivas bem-sucedidas (e, não raro, premiadas) são amplamente divulgadas pela mídia;porém, precisam ser problematizadas e relativizadas.

Um exemplo disso é o fato acontecido com uma professora do Ensino Fundamental que, diante de uma reportagem de revista sobre a inclusão de alunos com autismo, foi tomada pela angústia ao se deparar com um caso de inclusão bem-sucedido. A reportagem trazia a história de uma professora que, em uma turma de 30 alunos, havia tido sucesso ao incluir um aluno com autismo. Ao ouvir o teor da reportagem, a professora do Ensino Fundamental se colocou no lugar da colega e se perguntou sobre o que estaria fazendo de errado, uma vez que sua turma era de 14 alunos e ela se encontrava em um impasse frente ao seu aluno com autismo. Acolher o medo e o desconforto dos professores que trabalham com alunos tão singulares é um ato de coragem. Relatos como esse são pontuais, pois fazem com que o professor, ao falar das suas questões, realize um giro na sua posição e passe a se perguntar sobre quem é esse sujeito. Muitos deles saem da posição de queixa e começam a investir no seu aluno, desejosos de que a inclusão realmente aconteça.

Retornando ao discurso de documentos normativos, é relevante apreciarmos a Nota Técnica ${ }^{0}$ 24/2013 (BRASIL, 2013), que orienta os sistemas de ensino sobre a implementação da Política Nacional de Proteção dos Direitos da Pessoa com Transtorno do Espectro Autista, Lei $\mathrm{n}^{\circ}$ 12.764/2012 (BRASIL, 2012). Nesse documento, o autista é considerado uma pessoa com deficiência e, como tal, são assegurados a ele os direitos garantidos, por lei, aos sujeitos com deficiência. A Nota Técnica, além de asseverar o direito a um sistema educacional inclusivo em todos os níveis de ensino, orienta quanto à formação inicial e continuada dos profissionais da Educação, destacando a importância 
da avaliação pedagógica flexível, o estímulo à comunicação, as estratégias visuais de comunicação, a Comunicação Alternativa/Aumentativa, entre outros. Além de assegurar o direito à matrícula no ensino comum, o documento afirma que é garantido ao aluno com transtorno do espectro autista o Atendimento Educacional Especializado e o acesso a um profissional de apoio, disponibilizado pelo sistema de ensino, sempre que identificada a necessidade desse acompanhamento. Dessa forma, percebemos que esse documento traz orientações bastante diversas em relação ao trabalho pedagógico.

A Nota Técnica $n^{0}$ 24/2013 segue a esteira dos documentos publicados em anos anteriores, no que diz respeito ao tempo e ao espaço considerados mais indicados no processo de escolarização dos alunos com autismo. Nesse sentido, ela postula que a organização das atividades escolares deve ocorrer "[...] de forma compartilhada com os demais estudantes, evitando o estabelecimento de rituais inadequados, tais como: horário reduzido, alimentação em horário diferenciado, aula em espaços separados" (BRASIL, 2013, p. 3). Notamos, nesse excerto, novamente, um enunciado universalizante acerca do tempo e do espaço escolar para esses alunos. O texto da lei não abre exceções para aqueles alunos que, devido à sua condição subjetiva, poderão ter dificuldades para se enquadrar nas normas da escola. Paradoxalmente, essa nota apresenta orientações aos professores quanto a "parâmetros individualizados e flexíveis de avaliação pedagógica", "flexibilização mediante as diferenças de desenvolvimento emocional, social e intelectual dos estudantes com transtorno do espectro autista" e "[...] planejamento do atendimento educacional especializado considerando as características individuais de cada estudante que apresenta transtornos do espectro autista" (BRASIL, 2013, p. 3). Essas premissas indicam que as características individuais devem ser consideradas nas ações pedagógicas da escola, o que contradiz as orientações sobre a organização das atividades escolares, como consta na página três da Nota Técnica $\mathrm{n}^{0}$ 24/2013.

\section{ALGUMAS NOTAS PARA SEGUIR PERGUNTANDO}

O acompanhamento do processo de inclusão escolar de alunos com autismo nos permitiu constatar que alguns deles, especialmente nos primeiros anos escolares, apresentam dificuldades para, por exemplo, permanecer um turno inteiro em sala de aula. Muitas vezes, esses estudantes demonstram seu desconforto com o ambiente da sala de aula, expresso através do choro e da automutilação. Esses comportamentos revelam o quanto faltam palavras para expressar a dor frente a situações que eles não compreendem e que, por isso, têm um sentido real, petrificado. Nas palavras de Kupfer (2005, p. 24), "[...] os outros poderão ser localizados em uma posição ameaçadora, e essas 
crianças terão grande dificuldade em aceitar o barulho e a 'invasividade' dos outros ao seu redor". Em alguns momentos de muita desorganização psíquica, esses alunos precisam de um "agasalho humano" e de um espaço mais tranquilo para se acalmar. A sala de recursos multifuncionais pode ser esse espaço, apresentando-se como um refúgio onde o aluno permanecerá por um tempo para depois retornar à sala de aula.

Diante do que foi dito, na inclusão escolar de alunos com autismo a dinâmica pedagógica, que envolve os tempos e os espaços escolares, precisa ser repensada. Mediante algumas flexibilizações, observamos que muitos alunos conseguem, aos poucos, permanecer um tempo maior na escola e na sala de aula, passando a se interessar pelos artefatos do universo escolar. Essas flexibilizações permitem vislumbrar possibilidades de trabalho pedagógico que levam em conta a singularidade e que não se restringem somente à extinção de comportamentos mediante condicionamentos e treinamentos.

Vale salientar que, muitas vezes, as manifestações desses alunos poderão causar certo estranhamento aos professores que, em sua maioria, nunca se depararam com estudantes que apresentam estereotipias, dificuldades na relação com o outro, fala ecolálica e agitação. Esse estranhamento é expresso em frases como "Tem dias que minha sala de aula é uma loucura”, dita por uma professora em uma reunião pedagógica em que discutíamos possibilidades no processo de inclusão de alunos com autismo. Conforme afirma Pereira (2013), essas falas precisam ser ouvidas, pois revelam o desafio que é pensar o trabalho com alunos que, muitas vezes, se apresentam de forma errante no pátio da escola, rodando sobre seu próprio eixo ou caminhando sem rumo pelos labirintos da instituição. Outro importante recurso é o espaço de conversação para os professores, pois é no confronto das falas que eles podem se escutar e perceber que não estão sozinhos. É na circulação do discurso que, muitas vezes, o professor se apropria dos ditos dos colegas, tomando para si aquilo que lhe convier.

Ao observarmos as orientações em relação à inclusão de alunos com autismo, parece que uma série de prescrições de recursos pedagógicos e tecnológicos, que, com certeza, possuem relevância, seriam suficientes e garantiriam a aprendizagem desses sujeitos. Os recursos para o trabalho com esses alunos são também de outra ordem. É preciso pensarmos em outros tempos e espaços de circulação possíveis para essas crianças, dentro da escola e fora dela, analisando a flexibilidade que a complexidade dos casos exige. Problematizar as especificidades da escolarização desses estudantes viabiliza a criação de possibilidades de escolarização. É em um ato de invenção que o professor descobre, junto com seu aluno, quais estratégias pedagógicas utilizar.

Os professores, ao iniciarem o trabalho com esses alunos, demandam, muitas vezes, um método, um jeito de 
ensinar. Evidentemente, há especificidades que precisam ser consideradas, mas pensar em um método de ensino que seja "mais adequado" para todos os alunos com autismo não contribui para avançar nas questões referentes à educação desses sujeitos. Enquanto permanecermos no nível do ideal, na busca pela excelência nos processos de ensino e aprendizagem, mais nos afastaremos dos alunos.

A noção psicanalítica da singularidade propicia considerarmos o percurso escolar singular de cada um, evitando premissas universalizantes que poderiam obstaculizar o processo de inclusão do aluno real. Assim, seria possível levarmos em conta "[...] a particularidade do encontro aluno-professor-escola para o planejamento das ações pedagógicas" (LERNER, 2013, p. 146). Além disso, no que tange ao tempo escolar, poderíamos pensar em um tempo que é próprio de cada um. A partir dessa compreensão, uma educação para cada um seria uma possibilidade frente à educação para todos, pois o universal apaga a singularidade. As contribuições de Silva (2014) acerca da Educação Inclusiva previnem que o para cada um pode, por vezes, ser tomado como sob medida, pressupondo que "[...] haveria uma correspondência direta entre ' $\mathrm{O}$ ' diagnóstico e 'A' metodologia mais adequada, por exemplo" (SILVA, 2014, p. 210). Em uma educação sob medida o aluno "[...] reduzido ao significante incluído, quase como uma referência a uma etnia estrangeira supostamente homogênea, tornar-se-ia totalmente compreensível graças à captura e ao aprisionamento da sua singularidade por um discurso tecnocientífico" (SILVA, 2014, p. 210-211). Assim sendo, a ação pedagógica seria direcionada de acordo com o "diagnóstico" do aluno, favorecendo generalizações, fechando de forma hermética as possibilidades de invenção.

A referida autora avança em suas postulações, argumentando que:

Um anteparo possível a essa massificação é a aposta de que a educação, a despeito das exigências globais, precisaria reivindicar seu caráter artesanal. Dito de outro modo, só seria possível garantir um resíduo mínimo de singularidade, tanto para o professor quanto para o aluno, se a escola abrisse espaço (e tempo) para o trabalho artesanal, não serial, tecido a partir do (des)encontro entre professores e alunos. (SILVA, 2014, p. 239).

O trabalho artesanal permitiria o encontro singular com o aluno e as possibilidades particulares de escolarização poderiam ser tecidas. É na invenção de um espaço e de um tempo que está para além da convencionalidade do cotidiano escolar que permitiremos que a singularidade de cada sujeito apareça. É no caso a caso e diante das especificidades do processo de escolarização dos alunos com autismo que o tempo escolar poderá ser recriado, definindo o lugar de cada um diante da riqueza do que é ser humano. 


\section{REFERÊNCIAS}

AMARAL, Lígia Assumpção. Conhecendo a deficiência (em companhia de Hércules). São Paulo: Robe, 1995.

ARANHA, Maria Lúcia de Arruda. História da educação e da pedagogia. São Paulo: Moderna, 2006.

ARIÈS, Philippe. História social da criança e da família. Rio de Janeiro: LTC, 1978.

BANKS-LEITE, Luci; SOUZA, Regina Maria. O des(encontro) entre Itard e Victor: os fundamentos de uma Educação Especial. In: BANKS-LEITE, Luci; GALVÃO, Izabel (Org.). A educação de um selvagem: as experiências pedagógicas de Jean Itard. São Paulo: Cortez, 2000. p. 57-82.

BRASIL. Declaração Mundial sobre Educação para Todos. Satisfação das necessidades básicas de aprendizagem. 1990. Disponível em: <http://unesdoc.unesco.org/ images/o0o8/o00862/o86291por.pdf>. Acesso em: 28 nov.2015

BRASIL. Ministério da Educação. Declaração de Salamanca e linha de ação sobre necessidades educativas especiais. Sobre Princípios, Políticas e Práticas na Área das Necessidades Educativas Especiais, Brasília, DF, 1994. Disponível em: <http://portal.mec.gov.br/seesp/arquivos/pdf/salamanca.pdf>. Acesso em: 28 nov. 2015.

BRASIL. Lei no 9.394, de 20 de dezembro de 1996. Estabelece as diretrizes e bases da educação nacional. Brasília, DF, 1996. Disponível em: <http://www.planalto.gov. br/ccivil_03/Leis/L9394.htm>. Acesso em: 28 nov. 2015.

BRASIL. Ministério da Educação. Secretaria de Educação Especial. Grupo de Trabalho da Política Nacional de Educação Especial. Política nacional de educação especial na perspectiva da educação inclusiva, Brasília, DF, 2008. Disponível em: <http://portal.mec.gov. $\mathrm{br} /$ arquivos/pdf/politicaeducespecial.pdf $>$. Acesso em: 25 jun. 2012.

BRASIL. Ministério da Educação. Conselho Nacional de Educação. Câmara de Educação Básica. Resolução CNE/CEB no o4, de 2 de outubro de 2009. Institui as diretrizes estruturais e pedagógicas para o atendimento educacional especializado na educação básica modalidade Educação Especial. Brasília, DF, 2009. Disponível em: $<$ http://www.direitoaeducacao.org.br/ 1301/resolucao-cneceb-n\%C2\%BA-04-institui-as-diretrizes-estruturais-e-pedagogicas-para-o-atendimento-educacional-especializado-na-educacao-basica/ > . Acesso em: 1 mar. 2014. 
BRASIL. Ministério da Educação. Decreto No 7.611, de 17 de novembro de 2011. Dispõe sobre a Educação Especial, o Atendimento Educacional Especializado e dá outras providências. Brasília, DF, 2011. Disponível em: <http:// www.planalto.gov.br/ccivil_03/_ato2011-2014/2011/decreto/d7611.htm>. Acesso em: 28 nov. 2015.

BRASIL. Lei no 12.764, de 27 de dezembro de 2012. Institui a Política Nacional de Proteção dos Direitos da Pessoa com Transtorno do Espectro Autista; e altera o $\S$ $3^{\circ}$ do art. 98 da Lei no 8.112, de 11 de dezembro de 1990. Brasília, DF, 2012. Disponível em: <http://www.planalto. gov.br/ccivil_03/_ato2011-2014/2012/lei/l12764.htm >. Acesso em: 1 mar. 2014.

BRASIL. Nota Técnica no 24/2013/MEC/SECADI/ DPEE. Orientaçãoaos Sistemas de Ensino para aimplementação da Lei no 12.764/2012. Brasília, DF, 2013. Disponível em: <http://portal.mec.gov.br/index.php?option=com_ docman\&view = download\&alias $=13287-n$ t24-sistem-lei12764-2012\&category_slug=junho-2013pdf\&Itemid=30192> . Acesso em: 1 jan. 2014 .

CAMBI, Franco; TREBISACCE, Giuseppe. História da pedagogia. Tradução de Álvaro Lorencini. São Paulo: UNESP, 1999.

CARVALHO, Rosita Edler. Educação Inclusiva: do que estamos falando? Revista Educação Especial, Santa Maria, n. 26, p. 19-30, 2005.

CIRINO, Oscar. Psicanálise e psiquiatria com crianças: desenvolvimento ou estrutura. Belo Horizonte: $\mathrm{Au}-$ têntica, 2001.

COMENIUS, Jan Amos. A escola da infância. Tradução de Wojciech Andrzej Kulesca. São Paulo: Unesp, 2011.

DUSSEL, Inês; CARUSO, Marcelo. A invenção da sala de aula: uma genealogia das formas de ensinar. São Paulo: Moderna, 2003.

FREUD, Sigmund. Conferência XXXI: explicações, aplicações e orientações. In: FREUD, Sigmund. Obras completas de Sigmund Freud. Rio de Janeiro: Imago, 1988. v. 22. p.135-154.

GADOTTI, Moacir. História da idéias pedagógicas. São Paulo: Ática, 2002.

GAUTHIER, Clermont; TARDIF, Maurice. A pedagogia: teorias e práticas da antiguidade aos nossos dias. Petrópolis: Vozes, 2010.

GEOFFROY, Miriam Anne. A "instituição estourada" como "jogo do fort-da": de Jacques Lacan ao conceito de 
"instituição estourada" da escola Experimental de Bonneuil-Sur Marne. Tradução de Kelly Cristina Brandão da Silva. Revista Estilos da Clínica: revista sobre a infância com problemas, São Paulo, v. 9, n.17, p. 26-51, 2. sem. 2004 .

GHIRALDELLI JÚNIOR, Paulo. As concepções de infância e as teorias educacionais modernas e contemporâneas. Educação e Realidade, Porto Alegre, v. 25, n. 1, p. 45-58, 2000.

HAMILTON, David. Sobre a origem dos termos classe e curriculum. Teoria e Educação, Porto Alegre, n. 6, p. 33-52, 1996.

HILLESHEIM, Betina; GUARESCHI, Maria de Fátima. Contos de fadas e infância(s). Educação e Realidade, Porto Alegre, v. 31, n. 1, p. 107-126, 2006.

JANUZZI, Gilberta. A educação do deficiente no Brasil: dos primórdios ao início do século XXI. Campinas: Autores Associados, 2006.

JERUSALINSKY, Alfredo. Escolarização de crianças psicóticas. In: JERUSALINSKY, Alfredoet al.Psicanálise e desenvolvimento infantil. 3.ed. Porto Alegre: Artes e Ofícios, 2004. p.126-154.

KUPFER, Maria Cristina Machado. Educação terapêutica: o que a psicanálise deve pedir à educação. Estilos da Clínica: revista sobre a infância, São Paulo, v. 2, n. 2, p. 53-61, 2. sem. 1997.

KUPFER, Maria Cristina Machado. Psicose e autismo na infância: problemas diagnósticos. Estilos da Clínica: revista sobre a Infância, São Paulo, v. 4, n. 7, p. 96-107, 2. sem. 1999.

KUPFER, Maria Cristina Machado. Educação para o futuro: psicanálise e educação. 2. ed. São Paulo: Escuta, 2001.

KUPFER, Maria Cristina Machado. Inclusão Escolar: a igualdade e a diferença vistas pela psicanálise. In: KUPFER, Maria Cristina Machado; COLLI, Fernando Anthero Galvão (Org.). Travessias inclusão escolar: a experiência do grupo ponte - pré-Escola terapêutica lugar de vida. São Paulo: Casa do Psicólogo, 2005. p. 17-27.

LAJONQUIÈRE, Leandro de. Infância e ilusão (psico) pedagógica: escritos de psicanálise e educação. 3.ed. Rio de Janeiro: Vozes, 2002.

LAJONQUIÈRE, Leandro de.De Piaget a Freud: para repensar as aprendizagens: a (psico)pedagogia entre 
o conhecimento e o saber. 12.ed. Rio de Janeiro: Vozes, 2003 .

LAJONQUIÈRE, Leandro de; SCAGIOLA, Roberto. Conversando sobre Bonneuil: entrevistas com MaudMannoni, Marie-José Lérès e Lito Benvenutti. Revista Estilos da Clínica: revista sobre a infância com problemas, São Paulo, v. 3, n. 4, p. 20-40, 1. sem. 1998.

LERNER, Beatriz Coutinho. Consequências éticas da leitura psicanalítica dos quatro discursos para a Educação Inclusiva. 2013. $165 \mathrm{f}$. Tese (Doutorado em Educação)- Programa de Pós-Graduação em Educação, Universidade de São Paulo, São Paulo, 2013.

LOBO, Lilia Ferreira. Os infames da história: pobres, escravos e deficientes no Brasil. Rio de Janeiro: Lamparina, 2008.

MANNONI, Maud. Educação impossível. Rio de Janeiro: F. Alves, 1977.

MANNONI, Maud. Um lugar para Viver. Percurso, São Paulo, v. 1, n. 9, 2. sem. 1992.

MENDES, Enicéia Gonçalves. Breve histórico da educação especial no Brasil. Revista Educación y Pedagogía, Medellín, v. 22, n. 57, p. 93-109, maio/ago. 2010. Disponível em: <http://revinut.udea.edu.co/index.php/revistaeyp/article/viewArticle/9842>. Acesso em: 29 jan. 2014.

NARODOWSKI, Mariano. Comenius e a educação. Belo Horizonte: Autêntica, 2006.

NARODOWSKI, Mariano; HORS, Claudia van der. Orden y disciplina son el alma de la escuela. Educação e Realidade, Porto Alegre, v. 24, n. 1, p. 91-113, 1999.

O GAROTO selvagem. Direção: François Truffaut. Direção de produção: Jean-François Stévenin e Claude Miller. Intérpretes: François Truffaut; Jean-Pierre Cargol; Jean Dasté; Claude Miller; Jean-François Stévenin. [Paris]: Les Filmsdu Carrosse, 1970. 1 telefilme (83 min), son., p\&b.

PEREIRA, Marcelo Ricardo. Os profissionais do impossível. Educação \& Realidade, Porto Alegre, v. 38, n. 2, p. 485-499, abr./jun. 2013.

PETRI, Renata. Bonneuil: escola ou tratamento. Estilos da Clínica: revista sobre a infância, São Paulo, v. 3, n. 4, p. 90-95, 1. sem. 1998.

SANTIAGO, Ana Lydia. A inibição intelectual na psicanálise. Rio de Janeiro: Jorge Zahar, 2005. 
285 ALUNOS COM AUTISMO: UM ESTUDO DOS TEMPOS E DOS ESPAÇOS DE ESCOLARIZAÇÃO

SILVA, Kelly Cristina Brandão da. Educação Inclusiva: para todos ou para cada um? Alguns paradoxos (in)convenientes. 2014. 208 f. Tese (Doutorado em Educação)Programa de Pós-Graduação em Educação, Universidade de São Paulo, São Paulo, 2014.

VARELA, Julia. Categorias espaço-temporais e socialização escolar: do individualismo ao narcisismo. In: COSTA, Marisa Vorraber (Org.). Escola básica na virada do século: cultura, política e currículo. São Paulo: Cortez, 1996. p. 73-118.

Recebido em: 06/12/2016 Aprovado em: 12/04/2017 